\begin{tabular}{|c|c|c|c|c|}
\hline \multirow{2}{*}{ Sex } & \multirow{2}{*}{ Age (Years) } & \multicolumn{2}{|c|}{ Peak Acid Output (mEq/hr) } & \multirow{2}{*}{$\frac{\text { P.A.O. }}{\text { P.A.O. }} \times 100$} \\
\hline & & Histalog & Insulin & \\
\hline $\begin{array}{l}\mathrm{F} \\
\mathrm{M} \\
\mathrm{M}\end{array}$ & $\begin{array}{l}34 \\
66 \\
63\end{array}$ & $\begin{array}{c}18 \cdot 5 \\
1 \cdot 24 \\
17 \cdot 58\end{array}$ & $\begin{array}{l}0 \cdot 88 \\
0 \\
9 \cdot 54\end{array}$ & $\begin{array}{r}5 \\
0 \\
54\end{array}$ \\
\hline
\end{tabular}

results of gastric secretion tests ${ }^{8}$ are shown in the table.

These results could be interpreted as showing absence of impairment of vagal innervation of the stomach in these three patients with peripheral and autonomic neuropathy. Kassander ${ }^{9}$ had originally suggested that "a diabetic patient at some point in the progression of his diabetes may 'vagotomize' himself." Myelin degeneration has been seen in the vagal nerves of diabetics as well as in their peripheral nerves. ${ }^{10}$ Taken together these histological abnormalities ${ }^{10}$ and the gastric secretory studies ${ }^{578}$ support this concept of the diabetic vagotomizing himself, ${ }^{9}$ analogous to achalasia of the oesophagus. In 32 patients with achalasia vagal nerve function was considered absent in eight because of failure of acid response to insulin but adequate response to maximum Histalog stimulation. ${ }^{11}$ Autovagotomy should be considered as part of a spectrum of diabetic autonomic neuropathy, so that it is not surprising that the incidence of duodenal ulcer in diabetics is only one-third of that of the normal population. ${ }^{11}-\mathrm{I}$ am, etc.,

J. H. BARON

Department of Surgery,

Royal Postgraduate Medical School,

Hammersmith Hospital,

London W.12

1 Marks, I. N., Shuman, C. R., and Shay, H., Annals of Internal Medicine, 1959, 51, 227. Dotevall,

Angervall, L., Dotevall, G., and Lehmann, K. E., Fixa, B., et al.

Diseases, 1964,9, 494 Diseases, 1964, 9, 494.
Langer, L., Acta Medica Scandinavica, 1972,

6 Hunt, J. N., Lancet, 1950, 2, 397

Dotevali, G., et al., Acta Medica Scandinavica

Baron, J. H.. 1967, unpublished data.

9 Kassander, P., Annals of Internal Medicine, 1958, 48, 797.

Kristensson, K., et al., Acta Pathologica e

Wolam, G. L., Maher, F. T., and Ellis, F. H. Gastroenterology. 1967, 52, 1127 .

2 Dotevall, G., Acta Medica Scandinavica, 1959 164, 463.

\section{Death after E.C.T.}

SIR,-In her report of the death of a 55year-old woman following electric convulsion therapy (E.C.T.) Dr. Joan R. Gomez (6 July, p. 45) raises three points deserving consideration.

(1) The dangers of "cardiotoxic drugs" such as the tricyclic antidepressants used in conjunction with E.C.T. must be weighed against their advantages in preventing the fairly high incidence of early relapse (with risk of suicide) in patients treated with E.C.T. alone, ${ }^{12}$ particularly as giving additional E.C.T. after symptomatic relief has not been shown to prevent relapse. ${ }^{2}$ A number of studies do, however, suggest that concomitant tricyclic administration reduces the incidence of relapse. ${ }^{3}$

(2) Many investigators have commented unfavourably on the dosage and mode of atropine administration prior to E.C.T. ${ }^{5}$
Though Rich and Pitts, ${ }^{6}$ in a series of over 1,500 E.C.G.-monitored E.C.T.s, failed to demonstrate "anything approaching a lifethreatening vagal-induced arrythmia" using $0.65-2.5 \mathrm{mg}$ atropine by the subcutaneous route, pharmacological evidence suggests that the commonly used dosage of atropinethat is, $0.65 \mathrm{mg}$-is of placebo value only in preventing vagal inhibition.

(3) Acute anxiety resulting in sympathetic/ parasympathetic stimulation can undoubtedly be responsible for cardiac arrythmias; some anaesthetists in general surgical and dental practice are using such compounds as lorazepam intramuscularly as sole premedication with satisfactory results. It should be remembered, however, that most currently available effective anxiolytics also have anticonvulsant properties which might be antagonistic to the convulsant stimulus.-I am etc.

Department of Psychiatry,

JOHN L. BARTON

University of Psychir

Thomas, D. L. C., British Medical fournal, 1954

2. 950 .
Barton, J. L., Mehta, S., and Snaith, R. P., Acta Psychiatrica Scandinavica, 1973, 49, 386.

Seager, C. P., and Bird, R. L., fournal of Mental Science, 1962, 108, 704

Kay, D. W. K., Fahy, T., and Garside, R. F. British Fournal of Pschyiatry, 1970, 117, 667. 120, 355 .

Rich, C. L., and Pitts, F. N., jun., British fournal of Prych:atry, 1972, 121, 117 .

SIR-I was most interested by Dr. Joan $\mathbf{R}$ Gomez's letter (6 July, p. 45) reporting the death of a woman apparently from vagal inhibition due to the combination of electric convulsion therapy (E.C.T.) and amitriptyline and by her suggestion that the standard premedicating dose of atropine $(0.6 \mathrm{mg})$ is inadequate. After I had had a couple of nasty experiences (a cardiac arrest in grossly obese man who was fortunately easily resuscitated and a profound bradycardia in a young, apparently healthy man) I made it my standard practice to give atropine $1 \cdot 2$ mg intramuscularly at least an hour before E.C.T. and with this regimen $I$ found no further problems of this type, though I was averaging 50-60 E.C.T.s a week in a predominantly middle-aged and elderly population. Since peripheral circulation is often relatively impaired in patients under stress, it would be interesting to know by which route atropine was given to Dr. Gomez's patient and how long before the fatal E.C.T. I think one reason why the $0.6 \mathrm{mg}$ dose remains standard is because nearly all of us, doctors and nurses alike, tend to think of "drying up secretions" as being the main reason for giving atropine. Actually, if one stops to think logically about it, it is obvious that if one passes an electric current through the brain all the cranial nerves will be overstimulated and therefore one should use a dose of atropine sufficient to paralyse the vagus in order to avoid cardiac arrest.

Regarding Dr. Gomez's last question, surely the usual effect of anxiety on the heart is to produce a tachycardia, but it would be reasonable to suppose that this in itself may make the heart more vulnerable to further stimuli and also it is possible that the tachycardia might stimulate the vagus in an attempt at homoeostasis. In any case, as the patient was 55 at the time of her readmission it is probable that the E.C.T. she received for her puerperal illness would have been given without anaesthesia and so she may well have been far more apprehensive than are most patients prior to their first E.C.T.-I am, etc.,

Paula H. Gosling

Craig Phadrig Hospital,

Inverness

\section{Tests of Hearing in School}

SIR,-In your leading article (6 July, p. 3) doubt is expressed about school screen audiometric tests and it is suggested that perhaps impedance measurements for middle ear function could replace them. The article also gives incorrect information about the standard procedures.

School screen audiometry is carried out at $20-\mathrm{dB}$ levels, which is now the generally accepted standard, and all frequencies from 250 to $8,000 \mathrm{c} / \mathrm{sec}$ should be tested. Children should be tested as soon as possible after entry into the infants' school and again at the junior stage, but it is desirable to test all children, if at all possible, three times during their stay in the primary school. The value of this test is amply confirmed by direct experience from areas where school screen audiometry is practised properly. Extensive literature is available which clearly shows the importance of school screen audiometry, which is one of the most valuable methods of detecting children with previously unknown hearing losses, both conductive and sensorineural. Without this test many children with hearing losses would remain undetected.

From time to time, in order to check the results of school screen audiometry, groups of children who have failed the screen test and subsequent threshold audiometry test are examined by me at audiology clinics. Recently, in one group of 36 children I found 21 with a conductive loss and two with a sensorineural one; four had wax in their ears which needed syringing and nine had normal hearing. Of those with conductive loss, only three had already had E.N.T. treatment; six were referred by us for treatment for serous otitis media; seven needed further investigation and almost all of them needed some help and were visited at the school by a peripatetic teacher of the deaf. Of the two with a sensorineural hearing loss, one had a moderate high frequency one and one almost total unilateral deafness which had so far been undetected. Of the nine children with normal hearing, several had histories of variable conductive losses and needed further follow-up. Other checks have given similar results.

There is no doubt whatsoever that any school health service, without a properly organized audiometry programme neglects a very important aspect of school child health. The suggestion that impedance measurements should replace school screen audiometry reveals a lack of understanding of the functions of these tests. Many children are detected by school screen audiometry who would not be detected by the impedance 